Orbis Tertius, vol. XXV, $\mathrm{n}^{\circ}$ 32, e170, noviembre 2020-abril 2021. ISSN 1851-7811

Universidad Nacional de La Plata

Facultad de Humanidades y Ciencias de la Educación

Centro de Estudios de Teoría y Crítica Literaria

\title{
México, i9X3
}

Mario Bellatin

Cita sugerida: Bellatin, M. (2020). México, i9X3. Orbis

Tertius, 25(32), e170. https://doi.org/10.24215/18517811e170

$\mathrm{x} 8 \times 100,19 \times 3$

Blegir véxioo no lugar de la nuerte. La tierra donde los vivos conviven con los difuntos. Donde los perros Xololxoufntles, con sus cuerpos carentes de pelo y sus orejas glgantes como las de murcioliajos, son los enongados de lievar sobre sus lomos como las de murciliabos, son 103 enoarcondacirlos ppr el rlo correcto, donde 86 atraviesa lo Los 1dicados para tures es algo trascendente $y$ agul, on wat as tierra es parte de uns especlal comprension del rundo. Como si Manuel Puig hublera previsto que alrededor de su muerte estarian presentes otras muertes. Como al todo lo

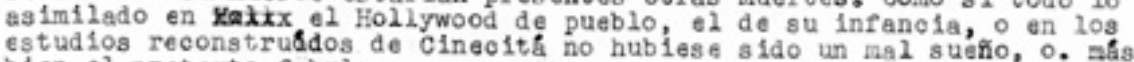
blen el pretexto fabuloso para pertenecer, Junto a Male, su madre, da quien no se separ\$sx odas a pesar de su errancla por el fiundo. La unjos mujer con la que mantuvo un estricto, estrict is 1 mo, pocas veces videa su vastedad $y$ en su lmpecable coonstrucoión, vinvulo epistolar. Cada carta un universo Puig. De ellos dos. De esa fantasia que tuvieron que inventar, de la cual debleron aferrarse para esopar de la realidad plana, vil, cerrada en 19 misma, de un p 000 poblodo de la pampa argentina. Luego dé las Erand6s bellezas de Italia, de la agitada y moderna vida de Nueva York, donde aparte de las cartas a su madre se atrevis a narras vifietas sord. das. Rouentros Pugeces. Impresiones tan abiertas y orudas, gue no $\mathbf{z e}$ atrevis a dejar por escrito an ninguno de sas libros. Las orbnteas a Nueva York fueron a Hell Kitchen. Su libro de Nueva Yorkr en casb1o, estaba cirounsorito a las ouatro calles que ofroundan Washington Squére, ese mismo Washington Suare de Henry Jases. Depurado por los interninables paseos entre un Joven que hacla de enfermero pXoxK, de paseador de enfermos, pare sostener sus estudios universitarios. Rl Mangel Puig de Brsil, románt1co a su manera. Voyeur de los amores semi urbanos. De esos incvs. fmores an zos arbustos lade ppr la masica popukar romintiva de la dir Sorfano, 0 narrando nelodia de Roberto Carlos. De Falalegria desoradadando no una vida de Rio de cuerpps desnudos, de la alegria desboradada entre la miseria propia do copacabana, Ipanezia $\mathrm{y}$ Leblen, No, al contrario, dos viojas lioran sus penas de lo que deben soportar en un Er1s Buenos Alres. Asplxiante. Agobladas las dos por las penurias de la vida. Calaveras zexicanas. Di. de Kuertos, que celebra el consuld Lowry. Cuernavacas. Mahuel Puig canina por las mismas. Colleds por las que, preclsamente un Dla de Nuertos, Pirmin muere en ls puerta de la cantine $\mathbb{Z}$. Farolito, $y$ su cuerpo es arrofado luego a una barranoa, como yn perro. Como mueren dlarfament $x$ miles de seres. De menera anon1ma. Mujeres, cuyos rostros vesos en todas las egaulbas de alumbrado, pr ' $\mathrm{As}$ estaclones de definido, Avidos gle nunesenou lo misma mujer tepetide encuentran a nacie. Porque es 1mposible hallar 10 10 gabla? Dstaba consoiente de que las Orquideas a la Luz de la luna so podian encontrar una escenografls semejante para ser lievada a oabo? alli su interis por entender al lengug le mex? que daban le impresion de transourrir todas en la cantina $\mathrm{k}$ perols en las exiate una explicacion coherente para tomar la decis $18 \mathrm{n}$ de habitar el lvger de la muerte feliz, por decirlo de alguna manere. $Y$ menos a cin la de internarse, por un mal menor, no una emergencia, en un sanatorfa de esos tue cuentan con la sala de embalsamamiento en la parte trasera. Decosos que correcta. Fin de la novela no esorita. Decision oryare alcanzer pues le faltaba el lengug fe De la elccion que nunva lagó. un momento, aln contaba con un jescrito para lograrlo, pero, je a inerpo vivo para lograrlb. 
Elegir México como lugar de la muerte. La tierra donde los vivos conviven con los difuntos. Donde los perros Xoloixcuintles, con sus cuerpos carentes de pelo y sus orejas gigantes como las de murciélagos, son los encargados de llevar sobre sus lomos a sus amos al Mictlán. Los indicados para conducirlos por el río correcto, donde se atraviesa lo que en otras culturas es algo trascendente y aquí, en estas tierras, es parte de una especial comprensión del mundo. Como si Manuel Puig hubiera previsto que alrededor de su muerte estarían presentes otras muertes. Como si todo lo asimilado en el Hollywood de pueblo, el de su infancia, o en los estudios reconstruidos de Cinecitá, no hubiese sido un mal sueño, o más bien el pretexto fabuloso para pertenecer, junto a Male, su madre, de quien no se separó más a pesar de su errancia por el mundo. La única mujer con la que mantuvo un estricto, estrictísimo, pocas veces visto en su vastedad y en su impecable construcción, vínculo epistolar. Cada carta un universo Puig. De ellos dos. De esa fantasía que tuvieron que inventar, de la cual debieron aferrarse para escapar de la realidad plana, vil, cerrada en sí misma, de un poblado de la pampa argentina. Luego de las grandes bellezas de Italia, de la agitada y moderna vida de Nueva York, donde aparte de las cartas a su madre se atrevió a narrar viñetas sórdidas. Encuentros fugaces. Impresiones tan abiertas y crudas, que no se atrevió a dejar por escrito en ninguno de sus libros. Las crónicas de Nueva York fueron su Hell's Kitchen. Su libro de Nueva York, en cambio, estaba circunscrito a las cuatro calles que circundan Washington Square, ese mismo Washington Square de Henry James. Depurado por los interminables paseos entre un joven que hacía de enfermero, de paseador de enfermos, para sostener sus estudios universitarios. El Manuel Puig de Brasil, romántico a su manera. Voyeur de los amores semi urbanos. De esos acercamientos de cuerpos insuflados por la música popular romántica de la época. Amores en los arbustos bajo la melodía de Roberto Carlos. De Waldir Soriano. O narrando no una vida de Río de cuerpos desnudos, de la alegría desbordada entre la miseria propia de Copacabana, Ipanema y Leblón. No, al contrario, dos viejas lloran sus penas de lo que deben soportar en un gris Buenos Aires. Asfixiante. Agobiadas las dos por las penurias de la vida. Calaveras mexicanas. Día de Muertos, que celebra el Cónsul de Malcom Lowry. Cuernavaca. Manuel Puig camina por las mismas calles por las que, precisamente un Día de Muertos, Firmin muere en la puerta de la cantina El Farolito, y su cuerpo es arrojado luego a una barranca, como un perro. Como mueren diariamente miles de seres. De manera anónima. Mujeres, cuyos rostros vemos en todas las esquinas. En los postes de alumbrado. En las estaciones de gasolina. Carteles que no tienen un fin definido. Avisos que nunca encuentran a nadie. Porque es imposible hallar a la misma mujer repetida en esos afiches hasta la saciedad. ¿Manuel Puig lo sabía? ¿Estaba consciente de que las Orquídeas a la Luz de la Luna sólo podían encontrar una escenografía semejante para ser llevada a cabo? De allí su interés por entender el lenguaje mexicano, que luego plasmó en las que daban la impresión de transcurrir todas en la cantina El Farolito. No existe una explicación coherente para tomar la decisión de habitar el lugar de la muerte feliz, por decirlo de alguna manera. Y menos aún la de internarse, por un mal menor, no una emergencia, en un sanatorio de esos que cuentan con la sala de embalsamamiento en la parte trasera. Decisión correcta. Fin de la novela no escrita. De la ficción que nunca llegó a alcanzar pues le faltaba el lenguaje escrito para lograrlo. Pero, un momento, aún contaba con un cuerpo vivo para lograrlo. 